\title{
SYNTHESIS, CHARACTERIZATION, AND ANTIBACTERIAL STUDY OF ZINC OXIDE-GRAPHENE NANOCOMPOSITES
}

\section{HARISH KUMAR*, MANISHA KUMARI}

Department of Chemistry, Material Science and Nano Materials Laboratory, Ch. Devi Lal University, Sirsa - 125 055, Haryana, India. Email: harimoudgil1@gmail.com

Received: 01 May 2017, Revised and Accepted: 27 May 2017

\section{ABSTRACT}

Objectives: A novel facile synthesis of zinc oxide (ZnO) and zinc-graphene oxide nanocomposites (ZnGONC) was achieved by modified sol-gel technique for their pharmaceutical and therapeutic use.

Materials and Methods: Spherical, crystalline, defect-free Zinc oxide nanoparticles (ZnO NPs) with diameter 70-90 nm were synthesized by modified sol-gel technique. Reduced graphene oxide was synthesized by modified Hummers method. ZnGONC were synthesized by in situ method. The crystalline nature, size, shape, and dimensions of the NPs, graphene oxide, and nanocomposites were studied by X-ray diffraction method. Transmission electron microscopy analysis was carried out to examine the morphology of NPs and nanocomposites.

Results: Fourier transform infrared spectroscopy analysis confirms that the ZnO NPs are surrounded by oxygen and silicon atoms. Antibacterial activity of ZnO NPs and ZnGONC was investigated against Gram-positive and Gram-negative bacteria. Zone of inhibition shown by ZnO NPs and ZnGONC was found to be higher than six investigated standard antibiotics.

Conclusion: Synthesized ZnO NPs and nanocomposites can be used as antibacterial agents. This eco-friendly method of synthesis of ZnO NPs and ZnGONC could be a viable solution for industrial applications in the future and therapeutic needs.

Keywords: Sol-gel, Zinc oxide nanoparticles, Optical properties, Nanocomposites, Antibacterial property.

(C) 2017 The Authors. Published by Innovare Academic Sciences Pvt Ltd. This is an open access article under the CC BY license (http://creativecommons. org/licenses/by/4. 0/) DOI: http://dx.doi.org/10.22159/ajpcr.2017.v10i9.19459

\section{INTRODUCTION}

Nanotechnology has emerged as a valuable modus in the pharmaceutical industry as an alternative antimicrobial approach because of arrival of antibiotic-resistant strains of microorganisms [1]. Nanosized particles, either simple or composite by nature, exhibit unique physical and chemical properties and show a potential of being used in various biomedical application [2-9]. There is a need to develop uniform nanosize drug particles having precise shape, size, and physical and chemical properties in the production of new pharmaceutical products. The biocidal efficiency of nanoparticles (NPs) may be due to combination of small size and high surface to volume ratio which facilitates intimate interactions with microbial membranes $[10,11]$.

Metal oxides with nanostructure have attracted considerable interest in many areas of technology [12]. Among metal oxide NPs, zinc oxide ( $\mathrm{ZnO}$ ) has received much attention in the recent past. $\mathrm{ZnO}$ nanostructures are the forefront of research due to their unique properties and wide applications such as ultraviolet blocking properties [13]. The advantage of using ZnO NPs is that they strongly inhibit the action of pathogenic microbes when used in small concentration [14].

Graphene oxide (GO) which is actually a compact honeycomb structure of $\mathrm{sp}^{2}$ hybridized carbon atoms has drawn a huge attention because of its outstanding electronic, thermal, and mechanical properties, which can be applied in nanomedicine field [15-20]. GO can be used to stabilize growing metal NPs and inhibits their aggregation because of its unique properties such as large surface area, low cytotoxicity, and good water stability. On these basis, GO and its composites have a wide range of possible applications on transistors, transparent conductors, polymer reinforcement, bioengineering, and biomaterials areas [21-23]
A lot of research has been carried out on antibacterial properties of Ag NPs and their nanocomposites. In continuation to our earlier study [24-30], in the present study, we have focused on the synthesis of zinc ( $\mathrm{Zn}$ ) NPs by facile, and cost effective sol-gel method and nanocomposite of $\mathrm{Zn}$ were prepared with reduced graphene oxide (RGO). Antibacterial properties of the synthesized NPs and nanocomposites were investigated against Gram-positive and Gram-negative bacteria. The aim of this study is to synthesize a nanocomposite material with better or comparable antibacterial performance.

\section{MATERIALS AND METHODS}

Materials

All chemicals used were of analytical reagent grade and used without further purification. Chemicals used were graphite powder $(<20 \mu)$, $\mathrm{ZnCl}_{2}, \mathrm{NaNO}_{3}, \mathrm{H}_{2} \mathrm{O}_{2}, \mathrm{H}_{2} \mathrm{SO}_{4}, \mathrm{KMnO}_{4}, \mathrm{HCl}, \mathrm{NaOH}, \mathrm{NaBH}_{4}$, citric acid, and ethylene glycol. All were available in our research lab. The strains employed in this work were the Gram-negative bacterium (Escherichia coli) and Gram-positive bacterium (Staphylococcus epidermidis). In addition, nutrient broth and agar-agar were used to prepare agar plates.

\section{Preparation of RGO}

GO was synthesized from graphite powder by a modified Hummers method [31]. Graphite powder, $\mathrm{NaNO}_{3}$, and $\mathrm{H}_{2} \mathrm{SO}_{4}$ were mixed together at $0.0^{\circ} \mathrm{C}$. Then, $\mathrm{KMnO}_{4}$ was added slowly into the reaction mixture with constant stirring. The mixture was heated to $35.0^{\circ} \mathrm{C}$ and stirred for $12.0 \mathrm{hrs}$, and then, $500.0 \mathrm{~mL}$ of water was slowly added under vigorous stirring. Then, $30.0 \% \mathrm{H}_{2} \mathrm{O}_{2}$ solution was added to reduce the residual $\mathrm{MnO}_{2}$. The mixture was then washed by acidified water $(3.0 \%)$ and then with double distilled water three times followed by filtration and drying. RGO sheets were then obtained. 
Preparation of ZnO NPs

$\mathrm{ZnCl}_{2}$ solution and citric acid solution were prepared separately in double-distilled water and were mixed together with continuous stirring for 15.0 minutes. Ethylene glycol was then added into the solution and continuously stirred for $3 \mathrm{hrs}$. The resultant precipitates thus obtained were washed with double-distilled water and then dried at $100.0^{\circ} \mathrm{C}$ in oven for $2.0 \mathrm{hrs}$. Finally, these were put into the muffle furnace at $600.0^{\circ} \mathrm{C}$ for $2.0 \mathrm{hrs}$. ZnO NPs were thus obtained.

\section{Preparation of $\mathrm{ZnO} / \mathrm{GO}$ nanocomposites}

$\mathrm{ZnCl}_{2}$ and $\mathrm{GO}$ were mixed together in double-distilled water to have a metal oxide loading of $10 \mathrm{wt} \%$. The solution $\mathrm{pH}$ was adjusted to 10.0 using $\mathrm{NaOH}$ solution and stirred continuously for $4.0 \mathrm{hrs}$. Then, $50 \mathrm{ml}$ of $0.1 \mathrm{M} \mathrm{NaBH}_{4}$ was added and stirred continuously for $3.0 \mathrm{hrs}$. The resulting material was then filtered and washed several times with double-distilled water and dried in oven at $80.0^{\circ} \mathrm{C}$. It was then calcined at $400.0^{\circ} \mathrm{C}$ for $3.0 \mathrm{hrs}$.

Table 1: ZOI (mm) shown by different standard antibiotics with Staphylococcus epidermidis and Escherichia coli

\begin{tabular}{llllllll}
\hline Bacterium & \multicolumn{7}{l}{ Standard antibiotics } \\
\cline { 2 - 7 } & TE 25 & C 25 & $\mathbf{P}_{\mathbf{1}}$ & AMP 10 & S 10 & S3 300 \\
\hline $\begin{array}{l}\text { Staphylococcus } \\
\text { epidermidis }\end{array}$ & 19 & 17 & 15 & NS & 23 & NS \\
Escherichia coli & 11 & 9 & NS & NS & 13 & NS \\
\hline
\end{tabular}

ZOI: Zone of inhibition

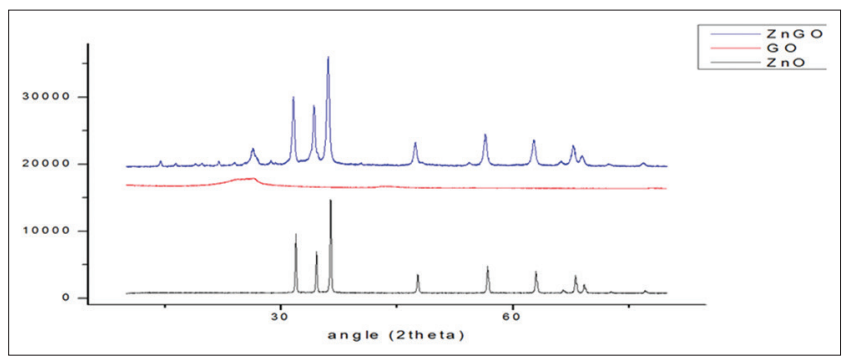

Fig. 1: X-ray diffractometer of zinc oxide nanoparticles, reduced graphene oxide, and zinc-graphene oxide nanocomposite

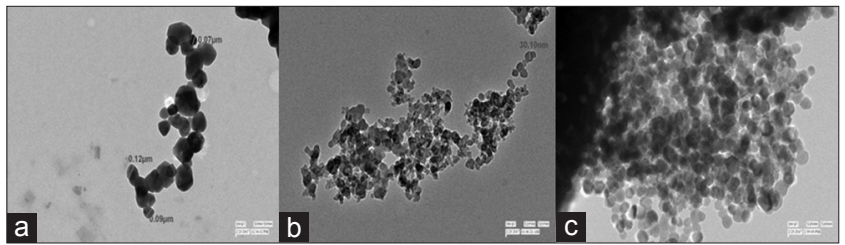

Fig. 2: Transmission electron microscopy images of (a) zinc oxide nanoparticles, (b) reduced graphene oxide, (c) zinc-graphene oxide nanocomposite

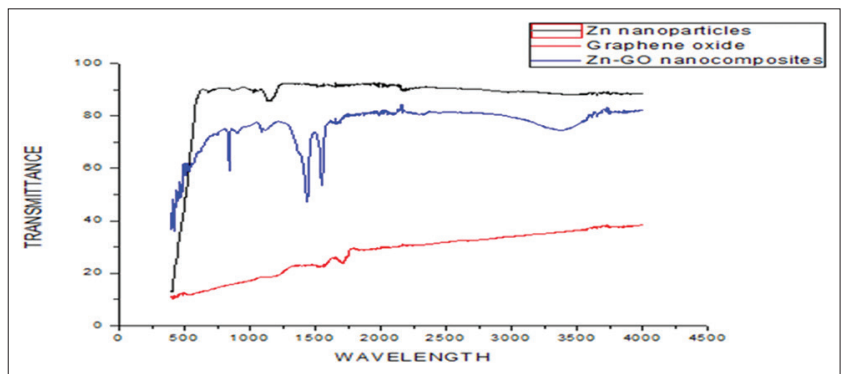

Fig. 3: Fourier transform infrared spectra of zinc oxide nanoparticles, reduced graphene oxide and zinc oxide graphene oxide nano-composites

\section{RESULTS AND DISCUSSION}

\section{Characterizations}

The X-ray diffraction pattern of the ZnO NPs and ZnO-GO nanocomposites samples were obtained (Fig. 1) using an X-ray diffractometer (XRD) (Panalyticals X.Pert Pro, P.U. Chandigarh). The XRD pattern of RGO indicates a broad diffraction peak at $2 \theta=24^{\circ}$. The broadening and shift of the characteristic diffraction peak of graphite from $26.58^{\circ}$ to $24^{\circ}$ in RGO which was due to the short-range order in stacked stacks. All XRD diffraction peaks of $\mathrm{ZnO}$ powders are shown in good agreement with hexagonal structure of $\mathrm{ZnO}$ reported in JCPDS File Card No. 050664. Peaks of $\mathrm{ZnO}$ at $31.7^{\circ}, 34.4^{\circ}, 36.2^{\circ}, 47.4^{\circ}, 56.6^{\circ}, 62.9^{\circ}, 65.5^{\circ}, 68.0^{\circ}$, and $69.1^{\circ}$ that are corresponding to (100), (002), (101), (102), (110), (103), (200), (112), and (201) lattice planes, respectively, indicating the formation of the wurtzite structure of ZnO NPs. No peaks of impurity are observed, indicating that the high purity $\mathrm{ZnO}$ was obtained. The XRD spectra of nanocomposites have peaks corresponding to both RGO and ZnO NPs.

The size, morphology, and distribution of $\mathrm{ZnO}$ NPs in ZnO-GO nanocomposites were examined using a transmission electron microscopy (TEM) (TECNAI $200 \mathrm{Kv}$ TEM [Fei, Electron Optics], AIIMS, Delhi). Fig. 2 shows TEM images of $\mathrm{ZnO}$ NPs, (a) RGO, and (b) ZnO-GO nanocomposite, and (c) the inset of Fig. 2a shows that the ZnO NPs have a spherical shape. The TEM image reveals that the ZnO NPs are dispersed on the GO (Fig. 2c). In addition, the TEM image shows an average particle size of approximately $90 \mathrm{~nm}$ for the NPs. From the TEM images, the GO surface looks smooth and integrated (Fig. 2b). In the case of $\mathrm{ZnO}-\mathrm{GO}$ nanocomposite (Fig. 2c), a large number of $\mathrm{ZnO}$ nanocomposites with average diameters $21.7 \pm 2.3 \mathrm{~nm}$ were observed

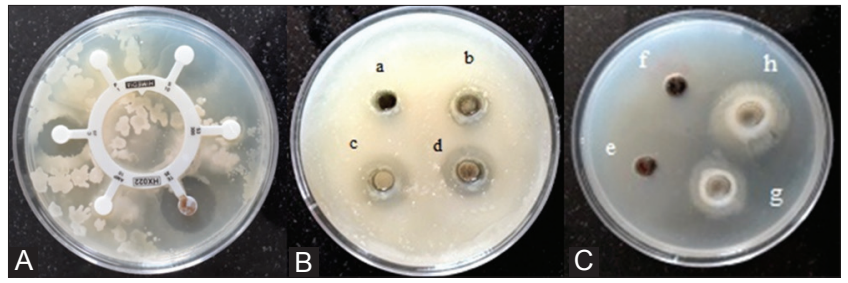

Fig. 4: (A) Zone of inhibition (ZOI) produced by different standard antibiotics with Staphylococcus epidermidis (B) and (C) different concentration of zinc oxide nanoparticles (ZnO-NPs) and $\mathrm{ZnO}$ graphene oxide (ZnO-GO) nanocomposites. ZOI produced with $S$. epidermidis, (a) $\mathrm{ZnSO}_{4}$, (b) $100 \mathrm{ppm}$ concentration of ZnO-NPs, (c) 500 ppm concentration of ZnO-NPs, (d) 1000 ppm concentration of $\mathrm{ZnO}-\mathrm{NPs}$, (e) $\mathrm{ZnSO}_{4}$ and grapheme, (f) $100 \mathrm{ppm}$ concentration of ZnO-GO nanocomposites, (g) 500 ppm concentration of ZnO-GO nanocomposites, (h) $1000 \mathrm{ppm}$ concentration of $\mathrm{ZnO}-\mathrm{GO}$ nanocomposites

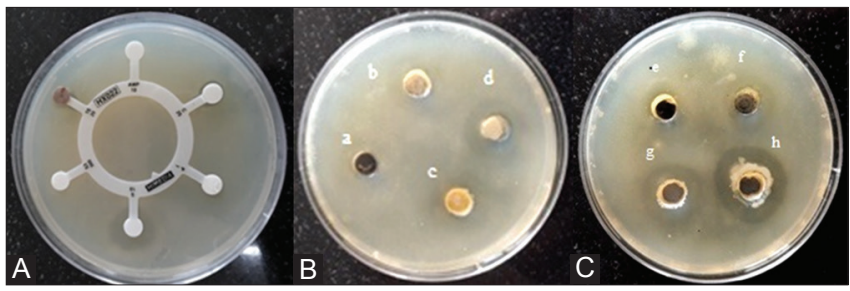

Fig. 5: Zone of inhibition (ZOI) produced by different standard antibiotics with Escherichia coli (A) and different concentration of zinc oxide nanoparticles (ZnO-NPs) (B) and ZnO-graphene oxide (GO) nanocomposites (C) with bacteria. ZOI produced with E. coli, (a) $\mathrm{ZnSO}_{4}$ (b) $100 \mathrm{ppm}$ concentration of $\mathrm{ZnO}-\mathrm{NPs}$, (c) $500 \mathrm{ppm}$ concentration of ZnO-NPs, (d) 1000 ppm concentration of $\mathrm{ZnO}$ $\mathrm{NPs}$, (e) $\mathrm{ZnSO}_{4}$ and grapheme, (f) $100 \mathrm{ppm}$ concentration of ZnO-GO nanocomposites, (g) 500 ppm concentration of $\mathrm{ZnO}$ GO nanocomposites, (h) 1000 ppm concentration of $\mathrm{ZnO}$-GO nanocomposites 
Table 2: Antibacterial effect of ZnO NPs and ZnO-GO nanocomposites against Gram-positive (Staphylococcus epidermidis) and Gram-negative (Escherichia coli) bacteria is indicated by measuring the diameter of ZOI ( $\mathrm{mm}$ )

\begin{tabular}{|c|c|c|c|c|c|c|c|c|}
\hline \multirow[t]{3}{*}{ Bacterial test organism } & \multicolumn{4}{|c|}{ Sample concentration in $\mu \mathrm{g} / \mathrm{ml}$} & \multicolumn{4}{|c|}{ Sample concentration in $\mu \mathrm{g} / \mathrm{ml}$} \\
\hline & \multirow{2}{*}{$\frac{\mathrm{ZnSO}_{4}}{1000}$} & \multicolumn{3}{|c|}{ ZnO NPs } & \multirow{2}{*}{$\begin{array}{l}\mathrm{ZnSO}_{4}+\text { graphene } \\
1000\end{array}$} & \multicolumn{3}{|c|}{ ZnO-GO nanocomposites } \\
\hline & & 100 & 500 & 1000 & & 100 & 500 & 1000 \\
\hline Staphylocoсcus epidermidis & 0 & 12 & 17 & 19 & 0 & 13 & 24 & 28 \\
\hline Escherichia coli & 0 & 16 & 19 & 21 & 10 & 17 & 20 & 23 \\
\hline
\end{tabular}

ZnO NPs: Zinc oxide nanoparticles, ZnO-GO: Zinc oxide-graphene oxide, ZOI: Zone of inhibition

uniformly on the surface of the GO. The high-magnification TEM image (Fig. 2c) further reveals that $\mathrm{ZnO}-\mathrm{GO}$ nanocomposites are almost spherical in shape.

The chemical functional groups of ZnO NPs and ZnO-GO nanocomposites were characterized using attenuated total reflectance Fourier transform infrared (FTIR) spectrometer (Perkin Elmer - Spectrum RX-IFTIR, P.U. Chandigarh). Fig. 3 shows FTIR spectra of ZnO NPs, RGO, and Zn-GO nanocomposites. In the FTIR spectrum for RGO, the peaks at 1731, 1625 , and $1183 \mathrm{~cm}^{-1}$ are assigned to the $\mathrm{C}=0$ stretching, $\mathrm{C}=\mathrm{C}$ stretching, and $\mathrm{C}-\mathrm{O}$ stretching, respectively. The broad peak at $3250 \mathrm{~cm}^{-1}$ in the FTIR spectrum of the ZnO-NPs/GO nanocomposite might be attributed to the $\mathrm{O}-\mathrm{H}$ stretching vibration of absorbed water molecules. The following functional groups were identified; O-H stretching vibrations (3240-3300 $\left.\mathrm{cm}^{-1}\right), \mathrm{C}=0$ stretching vibration $\left(1720-1740 \mathrm{~cm}^{-1}\right), \mathrm{C}=\mathrm{C}$ from un-oxidized $\mathrm{sp}^{2} \mathrm{C}-\mathrm{C}$ bonds $\left(1590-1620 \mathrm{~cm}^{-1}\right)$, and $\mathrm{C}-0$ vibrations $\left(1250 \mathrm{~cm}^{-1}\right)$ in the FTIR spectrum of $\mathrm{ZnO}-\mathrm{GO}$ nanocomposites which confirms the formation of nanocomposites.

\section{Antibacterial study}

The different researchers have reported antibacterial property of different metal NPs [32-35]. We have tested antibacterial activity of the $\mathrm{ZnO}$ NPs and ZnO-GO nanocomposites on Gram-positive $(S$. epidermidis) and Gram-negative (E. coli) bacteria using agar well diffusion method. Table 1 shows zone of inhibition (ZOI) (mm) shown by different standard antibiotics with S. epidermidis and E. coli. Table 2 shows antibacterial effect of ZnO NPs and ZnO-GO nanocomposites against Gram-positive (S. epidermidis) and Gram-negative (E. coli) bacteria are indicated by measuring the diameter of ZOI (mm). Fig. 4 shows that ZOI produced by different standard antibiotics with $S$. epidermidis (a) and different concentration of $\mathrm{ZnO}-\mathrm{NPs}$ and $\mathrm{ZnO}-\mathrm{GO}$ nanocomposites (b) and (c). Fig. 5 shows that ZOI shown by different standard antibiotics with $E$. coli (d) and different concentration of ZnONPs (e) and ZnO-GO nanocomposites (f) with bacteria.

Agar plates were prepared using nutrient broth and agar-agar. The wells of $8.0 \mathrm{~mm}$ diameter were punched with the help of steel borer into the agar having the test microorganism (at concentration about $5 \times 10^{5} \mathrm{CFU} / \mathrm{ml}$ ). The wells were filled with $100.0 \mu \mathrm{l}$ of $\mathrm{ZnO}$ NPs and $\mathrm{ZnO}-\mathrm{GO}$ nanocomposites of different concentration. A range of standard antibiotics (Hexa disc) was also used as the control. After 24.0 hrs incubation at $37.0^{\circ} \mathrm{C}$, the diameters of the inhibition zones were measured against the test microorganisms and optical images were documented by a high definition optical camera.

The highest ZOI shown by standard antibiotics is 23.0 and 13.0 for S. epidermidis and E. coli, respectively. The highest ZOI shown by ZnO $\mathrm{NP}$ and $\mathrm{ZnO}-\mathrm{GO}$ nanocomposites is 28.0 and 23.0 for $S$. epidermidis and E. coli, respectively. Hence, both $\mathrm{ZnO}$ and $\mathrm{ZnO-GO}$ nanocomposites show better antibacterial properties than six standard investigated antibiotics.

\section{CONCLUSION}

$\mathrm{ZnO} \mathrm{NPs}$, RGO, and $\mathrm{ZnO}-\mathrm{GO}$ nanocomposites have been prepared through facile and easy sol-gel methods. ZnO NPs samples exhibit good antibacterial activities against Gram-negative bacterial strain E. coli and Gram-positive strain S. epidermidis, but ZnO-GO nanocomposites exhibit better antibacterial activity. The increase of concentration of both $\mathrm{ZnO}$ NPs and $\mathrm{ZnO}-\mathrm{GO}$ nanocomposites results in increase in antibacterial activity. Antibacterial property of both, i.e., ZnO NPs and ZnO-GO nanocomposites was compared with six standard antibiotics. The highest ZOI shown by standard antibiotics is 23.0 and 13.0 for S. epidermidis and E. coli, respectively. Highest ZOI shown by ZnO NP and $\mathrm{ZnO-GO} \mathrm{nanocomposites} \mathrm{is} 28.0$ and 23.0 for S. epidermidis and E. coli, respectively. Hence, both $\mathrm{ZnO}$ and $\mathrm{ZnO}-\mathrm{GO}$ nanocomposites show better antibacterial properties than six standard investigated antibiotics.

\section{REFERENCES}

1. Desselberger U. Emerging and re-emerging infectious diseases. J Infect 2000;40(1):3-15

2. Chan WC, Nie S. Quantum dot bioconjugates for ultrasensitive nonisotopic detection. Science 1998;281(5385):2016-8.

3. Alivisatos AP. Semiconductor clustures, nanocrystal, and quantum dots. Science 1996;271(5251):933.

4. Chan WC, Maxwell DJ, Gao X, Bailey RE, Han M, Nie S. Luminescent quantum dots for multiplexed biological detection and imaging. Curr Opin Biotechnol 2002;13(1):40.

5. Wu X, Liu H, Liu J, Haley KN, Treadway JA, Larson JP, et al. Quantum dots for live cells. Nat Biotechnol 2003;21:41.

6. Brigger I, Dubernet C, Couvreur P. Nanoparticles in cancer therapy and diagnosis. Adv Drug Deliv Rev 2002;54(5):631-51.

7. Forestier F, Gerrier P, Chaumard C, Quero AM, Couvreur P, Labarre C. Effect of nanoparticle-boundampicillin on the survival of Listeria monocytogenes in mouse peritoneal macrophages. Antimicrob Chemother 1992;30(2):173-9.

8. Sondi I, Siiman O, Koester S, Matijevic E. Preparation of aminodextran-CdS nanoparticle complexes and biologically active antibody-aminodextran-CdS nanoparticle conjugates. Langmuir 2000;16(7):3107-18.

9. Siiman O, Matijevic E, Sondi I. Semiconductor nanoparticles for analysis of blood cell populations and methods of making same. U.S. Patent 6235540 B1.

10. Allaker RP. The use of nanoparticles to control oral biofilm formation. J Dent Res 2010;89(11):1175-86.

11. Morones JR, Elechiguerra JL, Camacho A, Holt K, Kouri JB, Ramírez JT, et al. The bactericidal effect of silver nanoparticles. Nanotechnology 2005;16:2346-53.

12. Sangeetha G, Rajeshwari S, Venckatesh R. Green synthesis of zinc oxide nanoparticlesby aloe barbadensis miller leaf extract: Structure and optical properties. Mat Res Bull 2011;46(12):2560-6.

13. Rouhi J, Mahmud S, Naderi N, Ooi CH, Mahmood MR. Physical properties of fish gelatin-based bio-nanocomposite films incorporated with ZnO nanorods. Nanoscale Res Lett 2013;8:364.

14. Applerot K, Wiberg E, Holleman AF. Inorganic Chemistry. Vol. 22. Amsterdam: Elsevier; 2009. p. 24-34

15. Novoselov KS, Geim AK, Morozov SV, Jiang D, Katsnelson MI, Grigorieva IV, et al. Two-dimensional gas of massless dirac fermions in graphene. Nature 2005;438(706):197-200.

16. Li X, Wang $X$, Zhang L, Lee S, Dai H. Chemically derived, ultra smooth graphene nanoribbon semiconductors. Science 2008;319(5867):1229-32.

17. Stankovich S, Dikin DA, Dommett GH, Kohlhaas KM, Zimney EJ, Stach EA, et al. Graphene-based composite materials. Nature 2006;442(7100):282-6.

18. Xiao W, Zhang YH, Liu BT. Raspberrylike $\mathrm{SiO}_{2} @$ reduced graphene oxide@AgNP composite microspheres with high aqueous dispersity and excellent catalytic activity. ACS Appl Mater Interfaces 2005;7(11):6041-6

19. Xiao W, Zhang Y, Tian L, Liu H, Liu B, Pu Y. Facile synthesis of 
reduced graphene oxide/titania compositehollow microspheres based on sonication-assisted interfacialself-assembly of tiny graphene oxide sheets and the photocatalytic property. J Alloys Compounds 2016;665(25):21-30

20. Schedin F, Geim AK, Morozov SV. Detection of individual gas molecules adsorbed on graphene. Nat Mater 2007;6(9):652-5.

21. Liao KH, Lin YS, Macosko CW, Haynes CL. Cytotoxicity of graphene oxide and graphene in human erythrocytes and skin fibroblasts. ACS Appl Mater Interfaces 2011;3(7):2607-15.

22. Ruiz ON, Fernando KA, Wang B, Brown NA, Luo PG, McNamara ND, et al. Graphene oxide: A nonspecific enhancer of cellular growth. ACS Nano 2011;5(10):8100-7.

23. Kavitha T, Gopalan AI, Lee KP, Park SY. Glucose sensing, photocatalytic and antibacterial properties of graphene- $\mathrm{ZnO}$ nanoparticle hybrids. Carbon 2012;50(8):2994-3000.

24. Sangwan P, Kumar H. Synthesis, characterization, and antibacterial activities of chromium oxide nanoparticles against Klebsiella pneumonia. Asian J Pharm Clin Res 2017;10(2):1-4.

25. Sangwan P, Kumar H, Purewal SS. Antibacterial activity of chemically synthesized chromium oxide nanoparticles against enterococcus Faecalis. Int J Adv Technol Eng Sci 2016;4(8):550-6.

26. Kumar H, Bhawana R. Synthesis of metal nanoparticles \& their use in electrochemical biosensors for the detection of microbes. Int J Ad Res Sci Eng 2016;5(8):751-61.

27. Rani R, Kumar H, Salar RK, Purewal SS. Antibacterial activity of copper oxide nanoparticles against gram-negative bacterial strain synthesized by reverse micelle route. Int J Pharm Res Dev 2014;6(1):72-8
28. Kumar H, Manisha P, Sangwan P. Synthesis \& characterization of $\mathrm{MnO}_{2}$ nanoparticles using co-precipitation technique. Int J Chem Chem Eng 2013;3(3):155-60.

29. Kumar H, Rani R. Structural characterization of silver nanoparticles synthesized by microemulsion route. Int $\mathrm{J}$ Eng Innov Technol 2013;3(3):344-8.

30. Kumar H, Rani R. Structural and optical characterization of $\mathrm{ZnO}$ nanoparticles synthesized by microemulsion route. Int Lett Chem Phys Astron 2013;14:26-36.

31. Hummers WS, Offeman RE. Preparation of graphitic oxide. J Am Chem Soc 1958;80(6):1339-9.

32. Bhatta P, Deepthib S, Kumarb $\mathrm{CH}$, Jha A. Facile synthesis, spectral studies, DFT calculations and biological activities of novel Ni (ii), $\mathrm{Cu}$ (ii), and Pd (ii) complexes of thiadiazole analogs. Int J Pharm Pharm Sci 2017;9(7):185-95.

33. Rohit M, Showkat RM, Saima A. Polymeric nanoparticles for improved bioavailability of cilnidipine. Int J Pharm Pharm Sci 2017;9(4):129-39.

34. Murugesan S, Bhuvaneswari S, Sivamurugan V. Green synthesis, characterization of silver nanoparticles of a marine red alga Spyridia fusiformis and their antibacterial activity. Int J Pharm Pharm Sci 2017;9(5):192-7.

35. Safdar MH, Hasan H, Anees M, Hussain Z. Folic acid-conjugated doxorubicin-loaded photosensitizing manganese ferrite nanoparticles: Synthesis, characterization and anticancer activity against human cervical carcinoma cell line (HELA). Int J Pharm Pharm Sci 2017;9(5):60-7. 